\title{
Prevalence and risk factors for maternal mortality in referral hospitals in Nigeria: a multicenter study
}

This article was published in the following Dove Press journal:

International Journal of Women's Health

Lorretta F Ntoimo, ${ }^{1,2}$ Friday E Okonofua, ${ }^{1,3,4}$ Rosemary $\mathrm{N}$ Ogu, 1,3,5 Hadiza S Galadanci, ${ }^{6}$ Mohammed Gana, ${ }^{7}$ Ola N Okike, ${ }^{8}$ Kingsley N Agholor, ${ }^{9}$ Rukiyat A Abdus-Salam, ${ }^{10}$ Adetoye Durodola," Eghe Abe, ${ }^{12}$ Abdullahi J Randawa ${ }^{13}$

On behalf of the WHARC WHO FMOH MNCH Implementation Research Study Team

' WHO Implementation Research Group, The Women's Health and Action Research Centre, Benin City, Edo State, ${ }^{2}$ Department of Demography and Social Statistics. Federal University Oye-Ekiti, Ekiti State, ${ }^{3}$ Centre of Excellence in Reproductive Health Innovation, University of Benin, Benin City, Edo State, ${ }^{4}$ Vice Chancellors Office, University of Medical Sciences, Ondo City, Ondo State, ${ }^{5}$ Department of Obstetrics and Gynaecology, University of Port Harcourt, Port Harcourt, Rivers State, ${ }^{6}$ Aminu Kano Teaching Hospital, Kano, Kano State, ${ }^{7}$ General Hospital, Minna, Niger State ${ }^{8}$ Karshi General Hospital, Federal Capital Territory, Abuja, ' $\mathrm{Central} \mathrm{Hospital,} \mathrm{Warri,}$ Delta State, ${ }^{10}$ Adeoyo Maternity Hospital, Ibadan, Oyo State, "'General Hospital, ljaye, Abeokuta, Ogun State, ${ }^{12}$ Central Hospital, Benin City, Edo State, ${ }^{13}$ Department of Obstetrics and Gynaecology, Ahmadu Bello University, Zaria, Kaduna State, Nigeria

Correspondence: Friday E Okonofua Vice Chancellors Office, University of Medical Sciences, Laje Road, Ondo City, Ondo State, Nigeria

Tel +2348023347828

Email vc@unimeds.edu.ng

Rosemary N Ogu

Department of Obstetrics and Gynaecology, University of Port Harcourt, East West Road, Port Harcourt 500102, Rivers State, Nigeria Tel +2348033129937

Email rosemary.ogu@uniport.edu.ng
Introduction: While reports from individual hospitals have helped to provide insights into the causes of maternal mortality in low-income countries, they are often limited for policymaking at national and subnational levels. This multisite study was designed to determine maternal mortality ratios (MMRs) and identify the risk factors for maternal deaths in referral health facilities in Nigeria.

Methods: A pretested study protocol was used over a 6-month period (January 1-June 30, 2014) to obtain clinical data on pregnancies, births, and maternal deaths in eight referral hospitals across eight states and four geopolitical zones of Nigeria. Data were analyzed centrally using univariate, bivariate, and multivariate statistics.

Results: The results show an MMR of 2,085 per 100,000 live births in the hospitals (range: $877-4,210$ per 100,000 births). Several covariates were identified as increasing the odds for maternal mortality; however, after adjustment for confounding, five factors remained significant in the logistic regression model. These include delivery in a secondary health facility as opposed to delivery in a tertiary hospital, non-booking for antenatal and delivery care, referral as obstetric emergency from nonhospital sources of care, previous experience by women of early pregnancy complications, and grandmultiparity.

Conclusion: MMR remains high in referral health facilities in Nigeria due to institutional and patient-related factors. Efforts to reduce MMR in these health facilities should include the improvement of emergency obstetric care, public health education so that women can seek appropriate and immediate evidence-based pregnancy care, the socioeconomic empowerment of women, and the strengthening of the health care system.

Keywords: maternal death, maternal mortality ratio, emergency obstetric care, pregnancy care, tertiary hospital

\section{Introduction}

With a currently estimated maternal mortality ratio of 814 per 100,000 live births, ${ }^{1}$ Nigeria has one of the highest ratios of maternal mortality in the world. Recent estimates by the World Health Organization indicate that not only did the country not achieve Goal-5 of the Millennium Development Goals that sought to reduce maternal mortality ratio by $75 \%$ by 2015 , but it also essentially witnessed a substantial increase in maternal deaths. $^{2}$ This is probably due to the fact that over the last 10 years, the intermediate indicators for achieving safe motherhood have not changed in the country. The contraceptive prevalence rate has remained low at $10 \% ;^{3}$ the rate of antenatal attendance by pregnant women has remained at $64 \%,{ }^{4}$ while the skilled birth attendance of $33 \%$ is one of the lowest in sub-Saharan Africa. ${ }^{5}$ With these abysmal indicators of maternal and reproductive health care, it is not surprising that no significant achievements have been made over the past decade in reducing maternal mortality in Nigeria. submit your manuscript Dovepress A http://dx.doi.org/10.21474JWH S151784
International Journal of Women's Health 2018:10 69-76

(c) (1) (-) 2018 Ntoimo et al. This work is published and licensed by Dove Medical Press Limited. The full terms of this license are available at https://www.dovepress.com/terms.php cc. hereby accept the Terms. Non-commercial uses of the work are permitted without any further permission from Dove Medical Press Limited, provided the work is properly attributed. For permission for commercial use of this work, please see paragraphs 4.2 and 5 of our Terms (https://www.dovepress.com/terms.php). 
Due to a poorly responsive health care system, most births in Nigeria occur in the homes of traditional birth attendants (TBAs) or in poorly managed private hospitals. ${ }^{6}$ When women in labor experience life-threatening complications, they are often referred to secondary and tertiary hospitals (referral hospitals) where they are managed as obstetric emergencies. The result may be maternal survival (near-miss cases) or death depending on the severity of the complication and the effectiveness and efficiency with which they are managed in the referral facilities. Consequently, most maternal deaths occur in referral facilities in the country, while deaths in basic obstetric care facilities and private clinics are few and often not recorded. ${ }^{7}$ The near complete absence of official registration of births and deaths in the country means that data from referral hospitals are the only available source of information on rates and trends in maternal deaths in the country.

Over the past decade, several publications have reported high maternal mortality ratios (MMRs), calculated as the number of maternal deaths per 100,000 deliveries in referral hospitals in Nigeria. ${ }^{8-12}$ While reports from individual hospitals have helped to provide substantial insights into the nature of the problem, they are often limited for policymaking at national and subnational levels. The results are useful for reform in the hospitals but are limited in their use for health systems reform and the identification of national policies and programs for preventing maternal deaths.

Thus, this study sought to determine MMRs and identify the risk factors for maternal deaths in referral hospitals in the country using the same period of analysis. To the best of our knowledge, this is one of the first multicenter comparative analysis of maternal deaths in referral facilities in Nigeria. We believe the results would be useful in designing policies and programs at the national and subnational levels for improving the quality of obstetric care and the management of obstetric complications that lead to maternal deaths in the country.

\section{Methods}

The study was a national multicenter study conducted in eight referral hospitals in eight states, in four out of the six geopolitical zones of the country. Data were collected from six secondary facilities and two tertiary hospitals.

The two tertiary hospitals were selected from the Northwest: Ahmadu Bello University Teaching Hospital, Kaduna and Aminu Kano Teaching Hospital, Kano. In contrast, the secondary care facilities were selected from the following three other zones: General Hospital, Ijaye, Abeokuta and Adeoyo Maternity Hospital in the Southwest;
General Hospital, Minna, Niger State and Karshi Hospital, Abuja in the North central; and Central Hospital, Benin City and Central Hospital, Warri from the South south.

A pretested protocol was used to obtain information on births and deaths in the hospital over the period of 6 months (January 1-June 30, 2014) preceding the study. Detailed retrospective reviews of records were undertaken from the case notes of 5,262 deliveries by women presenting for intrapartum care in the hospitals during the 6-month period. The information was extracted from the case notes available in the medical records departments of the hospitals, as well as from the daily records in the maternity and delivery sections of the hospitals. These included women with normal deliveries as well as those presenting with all complications managed in the hospitals during the period. Data extracted from the case notes included general sociodemographic data, as well as clinical presentation, and the history of current and past obstetric outcomes. We particularly documented the total number of deliveries and live births as well as the total number of all maternal deaths from each hospital during the period. Additional methods used to identify the number of maternal deaths in the hospitals included review of daily delivery records, review of records in the surgical departments, as well as records from maternal death reviews in hospitals that conduct periodic reviews of maternal deaths.

\section{Variables and measures}

The outcome variable was maternal mortality expressed as a binary variable: woman alive and woman died. Independent variables included type of facility (tertiary and secondary), and individual characteristics: parity $(0,1,2-4$, and $5+)$, age (in single years, and 5-year grouping except for 12-19 years), occupation (employed, self-employed, unemployed, and student), education (no formal education, primary, secondary, and tertiary), region (Northwest, North central, Southwest, and South south), and marital status (single mothers and married). Obstetric characteristics and history were booking for antenatal care (not booked and booked), referred from another facility (not referred and referred), number of early pregnancy lost in the past $(0,1-3,4+)$, experience of complications in the index pregnancy (yes and no), place of delivery (health facility, home/others), and mode of delivery (normal vaginal, cesarean section, others - ventouse, forceps, breech, and others).

\section{Statistical analysis}

Descriptive, bivariate, and multivariate analyses were conducted using Stata version 12 (StataCorp LP, College 
Station, TX, USA) for windows. The characteristics of the study population and prevalence of maternal mortality were presented using percentages and absolute numbers. MMR was calculated as number of deaths due to maternal causes per 100,000 live births within the period. The bivariate and multivariate analyses used logistic regression models to examine the unadjusted and adjusted odds ratios (ORs) of the association between the potential determinants and maternal mortality. The level of statistical significance (twotailed) was set at $p<0.05$. The multivariate analysis was not disaggregated by facilities due to the few cases of maternal death in some facilities. Some of the sociodemographic characteristics were not included in the multivariate model. For instance, there was only one case of death among women who were not in a union. Education had over $65 \%$ missing cases, so it was dropped from the analysis. Type of facility and region were highly correlated. Thus, separate models were estimated using each of them. The relationship between the independent variables and maternal death remained in the same direction (inverse or positive) and level of significance in the two models with slight difference in the ORs for each variable. Thus, only the table with type of facility is presented and the results for region are described.

\section{Ethical approval}

Ethical approval for the study was obtained from the World Health Organization and the National Health Research Ethics Committee (NHREC) of Nigeria (No. NHREC/01/01/200716/07/2014, renewed in 2017 with NHREC 01/01/2004712/12/2017b). The Chief Medical Directors, Heads of Departments of the hospitals were informed of the purpose of the study, and approvals were obtained for the extraction of data from case files. They were assured of the confidentiality of information obtained. Only the hospitals that agreed to participate in the fully explained study were enlisted. Informed consent from the patients to review their case files was waived due to the retrospective, non-interventional study design.

\section{Results Descriptive}

The distribution of the study population by facility and their background characteristics are presented in Table 1. The mean age of the mothers was 28.5 years (SD 5.5); 3.2\% were $<19$ years old, while $2.9 \%$ were over 39 years old. Many (31\%) were nulliparous and $37.3 \%$ were multiparous (parity $2-4)$. Most of the mothers completed secondary education (40\%); were self-employed (50.4\%); and $97.2 \%$ were in
Table I Percentage distribution of the study population by facility and other selected characteristics

\begin{tabular}{|c|c|c|}
\hline Characteristics & Number & $\%$ \\
\hline \multicolumn{3}{|l|}{ Hospital } \\
\hline Aminu Kano Teaching Hospital & 964 & 18.3 \\
\hline Karshi General Hospital, Abuja & 239 & 4.5 \\
\hline General Hospital, Minna & 511 & 9.7 \\
\hline Ahmadu Bello University Teaching Hospital, Zaria & 313 & 5.9 \\
\hline Adeoyo Maternity Hospital, Ibadan & $\mathrm{I}, 055$ & 20.0 \\
\hline Central Hospital, Benin City & $\mathrm{I}, 344$ & 25.5 \\
\hline State Hospital, ljaye, Abeokuta & 178 & 3.4 \\
\hline Central Hospital, Warri & 658 & 12.5 \\
\hline \multicolumn{3}{|l|}{ Type of facility } \\
\hline Tertiary & I,277 & 24.3 \\
\hline Secondary & 3,985 & 75.7 \\
\hline \multicolumn{3}{|l|}{ Region } \\
\hline Northwest & $\mathrm{I}, 277$ & 24.3 \\
\hline North central & 750 & 14.3 \\
\hline Southwest & 1,233 & 23.4 \\
\hline South south & 2,002 & 38.0 \\
\hline \multicolumn{3}{|l|}{ Booking status for antenatal care } \\
\hline Not booked & $\mathrm{I}, 820$ & 39.8 \\
\hline Booked & 2,750 & 60.2 \\
\hline \multicolumn{3}{|l|}{ Referral } \\
\hline Not referred & 4,205 & 91.6 \\
\hline Referred & 385 & 8.4 \\
\hline \multicolumn{3}{|l|}{ Age, years } \\
\hline $12-19$ & 160 & 3.2 \\
\hline $20-24$ & $\mathrm{I}, 047$ & 21.1 \\
\hline $25-29$ & 1,593 & 32.0 \\
\hline $30-34$ & I,385 & 27.9 \\
\hline $35-39$ & 640 & 12.9 \\
\hline $40-49$ & 146 & 2.9 \\
\hline \multicolumn{3}{|l|}{ Mean $(28.6 \pm 5.5)$} \\
\hline \multicolumn{3}{|l|}{ Parity } \\
\hline 0 & $\mathrm{I}, 550$ & 31.1 \\
\hline 1 & 1,200 & 24.0 \\
\hline $2-4$ & 1,860 & 37.3 \\
\hline $5+$ & 379 & 7.6 \\
\hline \multicolumn{3}{|l|}{ Education } \\
\hline No formal education & 342 & 18.1 \\
\hline Primary & 211 & 11.2 \\
\hline Secondary & 770 & 40.8 \\
\hline Tertiary & 565 & 29.9 \\
\hline \multicolumn{3}{|l|}{ Occupation } \\
\hline Employed & 607 & 16.0 \\
\hline Self-employed & 1,905 & 50.4 \\
\hline Unemployed & 1,103 & 29.2 \\
\hline Student & 168 & 4.4 \\
\hline \multicolumn{3}{|l|}{ Marital status } \\
\hline $\begin{array}{l}\text { Single mothers (never married/widowed/divorced/ } \\
\text { separated) }\end{array}$ & 89 & 2.1 \\
\hline Married & 4,107 & 97.9 \\
\hline \multicolumn{3}{|l|}{ Early pregnancy loss } \\
\hline 0 & 2,916 & 69.5 \\
\hline $1-3$ & 1,149 & 27.4 \\
\hline $4+$ & 132 & 3.1 \\
\hline \multicolumn{3}{|l|}{ Complication in index pregnancy } \\
\hline Yes & 601 & 15.2 \\
\hline No & 3,344 & 84.8 \\
\hline
\end{tabular}


Table I (Continued)

\begin{tabular}{lll}
\hline Characteristics & Number & $\%$ \\
\hline Place of delivery & & \\
Health facility & 4,416 & 98.6 \\
Home/others & 63 & 1.4 \\
Mode of delivery & & \\
Normal vaginal & 3,886 & 86.9 \\
Cesarean section & 514 & 11.5 \\
Others & 74 & 1.6 \\
\hline
\end{tabular}

Notes: Missing cases: booking status: 692; referral: 672; age: 291; parity: 273; education: 3,374; occupation: I,479; marital status: 1,066; early pregnancy loss: I,065; complications in index pregnancy: 1,3 I7; place of delivery: 783; and mode of delivery: 788 .

marital union. Close to $40 \%$ never booked for antenatal care (unbooked women), while 8.4\% were referred from TBAs and homes. In the index pregnancy, $15.2 \%$ experienced complications, $98.6 \%$ delivered in health facilities, and the mode of delivery for most of the births was normal vaginal birth.

MMR in each facility is shown in Table 2. There were 5,262 births in the hospitals, out of which 4,363 (82.9\%) were live births and 91 maternal deaths. Taken together, the MMR for the 6 months in the hospitals was 2,085 per 100,000 live births. Extremely high MMR was recorded in all the facilities except Aminu Kano Teaching Hospital and Adeoyo Maternity Hospital where MMR was $<1,000$ per 100,000 live births.

The obstetric causes of maternal deaths in the health facilities are presented in Table 3. There were diverse and multiple causes of deaths, which varied widely between the health facilities. Overall, primary postpartum hemorrhage, eclampsia, obstructed labor, and puerperal sepsis were the leading causes of maternal mortality.

The prevalence of maternal deaths across the facilities and selected background characteristics of the mothers are shown in Table 4. Maternal deaths were highly prevalent in the secondary facilities (84.6\%), among unbooked cases

Table 2 MMRs by health facility

\begin{tabular}{llll}
\hline Hospitals & $\begin{array}{l}\text { No of live } \\
\text { births }\end{array}$ & $\begin{array}{l}\text { No of } \\
\text { deaths }\end{array}$ & $\begin{array}{l}\text { MMR/I00,000 } \\
\text { live births }\end{array}$ \\
\hline Aminu Kano Teaching Hospital & 825 & 8 & 969 \\
Karshi General Hospital, Abuja & 234 & 6 & 2,564 \\
General Hospital, Minna & 380 & 16 & 4,210 \\
Ahmadu Bello University & 277 & 6 & 2,166 \\
Teaching Hospital & & & \\
Adeoyo Maternity Hospital & 912 & 8 & 877 \\
Central Hospital, Benin City & 1,036 & 31 & 2,992 \\
State Hospital, ljaye, Abeokuta & 164 & 4 & 2,439 \\
Central Hospital, Warri & 535 & 12 & 2,243 \\
Total & 4,363 & 91 & 2,085
\end{tabular}

Abbreviation: MMR, maternal mortality ratio.
(58.8\%), unreferred clients (76.2\%), and multiparous mothers $(41.6 \%)$. There were more maternal deaths in the South south $(47.3 \%)$ and North central $(24.2 \%)$ regions than in the Northwest (15.4\%) and Southwest (13.2\%) regions. More mothers who were self-employed (44.9\%) or unemployed (40.6) died from maternal causes than those who were employed (8.7\%). More deaths were recorded among married mothers $(98.8 \%)$ than their single counterparts (1.2\%). About $36 \%$ of the mothers who died experienced early pregnancy loss in the past; $31 \%$ reported complications in the index pregnancy, while $23 \%$ of maternal deaths were among women who gave birth through elective and emergency cesarean section.

\section{Bivariate and multivariate}

A logit model was used to determine the predictors of maternal mortality in the health facilities (Table 5). Column 1 shows the bivariate model with the unadjusted OR for each predictor. The results indicate that early booking for antenatal care in the health facilities (OR $0.45, p<0.001)$ and no complications in the index pregnancy (OR $0.38, p<0.001$ ) were significantly associated with reduced risk of maternal death. In contrast, high odds of maternal mortality were significantly associated with delivery in secondary facilities, referred women, multiparity, grand multiparity, and unemployed mothers. Maternal mortality was also more likely among mothers who experienced $\geq 4$ early pregnancy losses in the past, those who delivered at home or with a TBA, and among those who had a cesarean section.

At the multivariate level (column 2), all the variables were entered into the regression model to determine independent predictors of maternal mortality in the health facilities. The analysis showed that the odds of maternal mortality were over three times higher in the secondary facilities than in the tertiary hospitals (OR 3.80, $p<0.05$ ). The likelihood of death was $68 \%$ lower for mothers who booked for antenatal care than for those who did not (OR 0.32, $p<0.01)$. Clients who were referred to the facilities from homes and TBAs were more likely to die than those who were not referred (OR 2.70, $p<0.05$ ). Relative to nulliparous mothers, those who had $\geq 1$ birth before the index pregnancy were more likely to die; the odds significantly increased with higher parity. Experience of $\geq 4$ early pregnancy losses increased the odds of maternal mortality (OR 7.98, $p<0.01$ ).

In the model with region (table not shown), the odds of maternal death were significantly higher in the North central (OR 3.07, $p<0.01$ ) and South south (OR 2.04, $p<0.05$ ) regions compared to the Northwest. In the adjusted model, 
Table 3 Distribution of maternal deaths by discharge diagnosis and facility

\begin{tabular}{|c|c|c|c|c|c|c|c|c|c|}
\hline Discharge diagnosis (n) & АКТН & KGH & GH & ABUTH & AMH & CHB & SHI & CHW & Total \\
\hline Other causes** & & & 14 & & & 13 & 2 & 12 & 41 \\
\hline Aspiration pneumonitis & 2 & & & & & & & & 2 \\
\hline Cephalopelvic disproportion & & & 1 & & & 1 & & & 1 \\
\hline Eclampsia & 2 & 6 & & & & 10 & 1 & & 19 \\
\hline Postpartum hemorrhage & 4 & & 1 & 6 & 8 & 2 & & & 21 \\
\hline Ruptured uterus & & & & & & 1 & I & & 2 \\
\hline Puerperal sepsis & & & & & & 4 & & & 4 \\
\hline Total & 8 & 6 & 16 & 6 & 8 & 31 & 4 & 12 & 91 \\
\hline
\end{tabular}

Notes: **Other causes include anemia, sickle cell disease, ectopic pregnancy, antepartum hemorrhage, thromboembolism, acute renal failure, HIV/AIDS, disseminated intravascular coagulopathy, and meningitis.

Abbreviations: AKTH, Aminu Kano Teaching Hospital, Kano; KGH, Karshi General Hospital, Abuja; GH, General Hospital, Minna; ABUTH, Ahmadu Bello University Teaching Hospital, Kaduna; AMH, Adeoyo Maternity Hospital, Ibadan; CHB, Central Hospital, Benin City; SHI, Specialist Hospital, ljaye, Abeokuta; CHW, Central Hospital, Warri.

a significant relationship remained for Northwest (OR 6.02, $p<0.01)$ and became insignificant for South south. The relationship between maternal mortality and other variables remained significant and in the same inverse or positive direction, with slight differences in the ORs.

\section{Discussion}

The objective of the study was to determine the prevalence and risk factors for maternal mortality in referral hospitals in Nigeria. The results show high MMRs in the eight hospitals, which are much higher than the reported mean maternal mortality ratio in the country. ${ }^{2}$ This is not surprising as these hospitals are designated to receive and manage obstetric referrals from primary health care settings and also to deal with severe complications of pregnancy. However, the MMRs reported in this study are much higher than those reported from similar health facilities in other lowincome countries, ${ }^{13-15}$ which suggest a particularly severe problem in the country.

The reported MMR in this study ranged between 877 per 100,000 live births and 4,210 per 100,000 births; the mean MMR in the eight hospitals was 2,085 per 100,000 live births, while six out of the eight hospitals reported an MMR in excess of 2,000 per 100,000 live births. In contrast, several secondary and tertiary hospitals in Ghana report MMR values $<1,200$ per 100,000 live births. ${ }^{16,17}$ Indeed, a report from the Tamale Teaching Hospital in Ghana revealed a decline in MMR by $74 \%$ from 1,870 per 100,000 births in 2006 to 493 per 100,000 in 2010, through a systematic approach by the hospital to address the problem of high rates of maternal mortality. Similar recent data from South Africa ${ }^{18}$ reported a simmering MMR of 1,579 per 100,000 live births at the Petersburg Hospital in the Limpopo province, much lower than the average figure in this report. The high MMR in referral hospitals in this study is possibly indicative of the poor state of emergency obstetric care in referral hospitals in Nigeria, which have been reported in several previous publications. ${ }^{7,11,19-21}$ Thus, it is evident that poor quality emergency obstetric care needs to be urgently addressed as part of efforts to reduce MMR in referral facilities in the country.

Several factors were identified in this study as increasing the likelihood of maternal mortality. These include nonbooking for antenatal care, referral from lower level health/ non-health facilities, delivery in secondary health facilities as compared to tertiary facilities, multiparity, grand multiparity, and unemployment status. However, after controlling for confounding variables, delivery in secondary facilities, nonbooking status, referral from lower level health facilities, multiparity, grandmultiparity and past experiences of early pregnancy loss remained significant in the logistic regression model. In contrast, the results show that the odds of maternal death were significantly reduced by report of antenatal care attendance. Although previous reports have identified high MMRs in referral facilities in Nigeria, ${ }^{22,23}$ this is possibly the first report that shows higher MMR in secondary facilities as compared to tertiary hospitals using the same data set. Although both types of hospitals have traditionally provided emergency obstetric care in the country, there has been less attention devoted to providing human and infrastructural resources for care in secondary as compared to tertiary hospitals. This may be due to the fact that tertiary hospitals are managed by the Federal Ministry of Health, while secondary hospitals are managed by States Ministries of Health that allocate limited resources to health. Many Nigerian states often do not prioritize resource allocation to health, which accounts for the poor quality of maternal health care and emergency obstetric care in secondary care hospitals. The results of this study point to the need for Nigerian States to take steps to strengthen their health care systems, especially the delivery of emergency obstetric care in secondary health facilities. 
Table 4 Prevalence of maternal deaths by facility and selected maternal characteristics

\begin{tabular}{|c|c|c|}
\hline Characteristics & Number & $\%$ \\
\hline \multicolumn{3}{|l|}{ Type of facility } \\
\hline Tertiary & 14 & 15.4 \\
\hline Secondary & 77 & 84.6 \\
\hline \multicolumn{3}{|l|}{ Region } \\
\hline Northwest & 14 & 15.4 \\
\hline North central & 22 & 24.2 \\
\hline Southwest & 12 & 13.2 \\
\hline South south & 43 & 47.3 \\
\hline \multicolumn{3}{|l|}{ Booking status for antenatal care } \\
\hline Not booked & 50 & 58.8 \\
\hline Booked & 35 & 41.2 \\
\hline \multicolumn{3}{|l|}{ Referral } \\
\hline Not referred & 64 & 76.2 \\
\hline Referred & 20 & 23.8 \\
\hline \multicolumn{3}{|l|}{ Age, years } \\
\hline $12-19$ & 4 & 4.5 \\
\hline $20-24$ & 24 & 27.3 \\
\hline $25-29$ & 22 & 25.0 \\
\hline $30-34$ & 22 & 25.0 \\
\hline $35-39$ & 14 & 15.9 \\
\hline $40-49$ & 2 & 2.3 \\
\hline \multicolumn{3}{|l|}{ Parity } \\
\hline 0 & 17 & 19.1 \\
\hline 1 & 25 & 28.1 \\
\hline $2-4$ & 37 & 41.6 \\
\hline $5+$ & 10 & 11.2 \\
\hline \multicolumn{3}{|l|}{ Education } \\
\hline No formal education & 12 & 25.0 \\
\hline Primary & 8 & 16.7 \\
\hline Secondary & 20 & 41.7 \\
\hline Tertiary & 8 & 16.7 \\
\hline \multicolumn{3}{|l|}{ Occupation } \\
\hline Employed & 6 & 8.7 \\
\hline Self-employed & 31 & 44.9 \\
\hline Unemployed & 28 & 40.6 \\
\hline Student & 4 & 5.8 \\
\hline \multicolumn{3}{|l|}{ Marital status } \\
\hline $\begin{array}{l}\text { Single mothers (never married/ } \\
\text { widowed/divorced/separated) }\end{array}$ & 1 & 1.2 \\
\hline Married & 85 & 98.8 \\
\hline \multicolumn{3}{|l|}{ Early pregnancy loss } \\
\hline 0 & 45 & 63.4 \\
\hline $1-3$ & 20 & 28.2 \\
\hline $4+$ & 6 & 8.4 \\
\hline \multicolumn{3}{|l|}{ Complication in index pregnancy } \\
\hline Yes & 22 & 31.0 \\
\hline No & 49 & 69.0 \\
\hline \multicolumn{3}{|l|}{ Place of delivery } \\
\hline Health facility & 70 & 93.3 \\
\hline Home/others & 5 & 6.7 \\
\hline \multicolumn{3}{|l|}{ Mode of delivery } \\
\hline Normal vaginal & 54 & 73.0 \\
\hline Cesarean section & 17 & 23.0 \\
\hline Others & 3 & 4.0 \\
\hline
\end{tabular}

Notes: Missing cases: booking status: 6; referral: 7; age: 3; parity: 2; education: 43; occupation: 22; marital status: 5; early pregnancy loss: 20 ; complications in index pregnancy: 20; place of delivery: 16; and mode of delivery: 17.
As shown in this study, non-booking for antenatal care and the referral of women from health facilities after they experience complications in labor from other settings were significantly associated with increased risks of maternal death. Non-booking for antenatal and delivery care and late presentation in labor have repeatedly been reported as causes of delays that lead to maternal deaths in many parts of the country. ${ }^{22,24}$ Several demand and supply factors have been reported as reducing women's access to antenatal, delivery, emergency obstetric, and postnatal care in various parts of the country. These include inability to pay for services, perceptions relating to unfriendly health providers, fear of medical interventions (in particular cesarean sections), cultural beliefs, and difficulty with transportation among others. Efforts to address these bottlenecks and also provide substantive education to women on the benefits of early booking for pregnancy care will reduce non-booking and delayed referral as intermediate determinants of maternal mortality.

The results of this study show that maternal sociodemographics and clinical variables, specifically grand multiparity, past experiences of early pregnancy loss, and maternal unemployment featured as significant independent risk factors for maternal mortality. In particular, grand multiparity ( $>$ para 5) increased the odds of maternal mortality by nearly sevenfold, while women's self-report of previous early pregnancy loss ( $>4$ times) significantly increased the likelihood of maternal deaths eight times over women who have not experienced early pregnancy loss. This implies that efforts to reduce maternal deaths need to be concentrated in building the agency of women to handle all aspects of pregnancy care, especially to strategically handle women with previous pregnancies especially those with previous adverse birth outcomes. Some specific measures that need to be undertaken include the provision of maternal health education to women, the promotion of family planning, and provision of social safety nets (including free maternal health care) to ensure that women are not denied the benefits of evidence-based pregnancy care because of inability to pay for services.

The major strength of this study is its multicenter design and its involvement of multiple hospitals in different geopolitical zones in the country. This has allowed regional comparison of the results, permitting its generalization to the wider Nigerian health systems context. The results are not only usable for changing the management of maternal health care within the participating health facilities, they also have implications for the development of policies for the improvement of maternal health care and obstetric emergency care in the country. 
Table 5 Logistic regression model predicting the determinants of maternal mortality in referral hospitals in Nigeria

\begin{tabular}{|c|c|c|c|c|}
\hline \multirow[t]{2}{*}{ Variables } & \multicolumn{4}{|c|}{ OR and $95 \% \mathrm{Cl}$} \\
\hline & Unadjusted & $\mathrm{Cl}$ & Adjusted & $\mathrm{Cl}$ \\
\hline \multicolumn{5}{|l|}{ Type of facility } \\
\hline Tertiary (RC) & 1.00 & & 1.00 & \\
\hline Secondary & $1.84^{*}$ & $1.04-3.28$ & $3.80 *$ & $1.15-12.5$ \\
\hline \multicolumn{5}{|c|}{ Booking status for antenatal care } \\
\hline Not booked (RC) & 1.00 & & 1.00 & \\
\hline Booked & $0.45^{* * *}$ & $0.29-070$ & $0.32 * *$ & $0 .|5-0.7|$ \\
\hline \multicolumn{5}{|l|}{ Referral } \\
\hline Not referred $(\mathrm{RC})$ & 1.00 & & 1.00 & \\
\hline Referred & $3.41^{* * *}$ & $2.04-5.7 \mathrm{I}$ & $2.70 *$ & $1.05-6.93$ \\
\hline Age & 0.98 & $0.95-1.02$ & 0.96 & $0.88-1.04$ \\
\hline \multicolumn{5}{|l|}{ Parity } \\
\hline $0(\mathrm{RC})$ & 1.00 & & 1.00 & \\
\hline 1 & 1.84 & $0.99-3.44$ & $3.87^{*}$ & $1.27-11.8$ \\
\hline $2-4$ & I.78* & $0.99-3.18$ & $4.33 *$ & $1.28-14.5$ \\
\hline $5+$ & $2.38^{*}$ & $1.08-5.25$ & $6.89 *$ & $1.26-37.6$ \\
\hline \multicolumn{5}{|l|}{ Occupation } \\
\hline Employed (RC) & 1.00 & & 1.00 & \\
\hline Self-employed & 1.70 & $0.70-4.11$ & 1.07 & $0.29-3.86$ \\
\hline Unemployed & $2.56^{*}$ & $1.05-6.22$ & 2.40 & $0.59-9.77$ \\
\hline Student & 2.49 & $0.69-8.97$ & 3.42 & $0.48-24.0$ \\
\hline \multicolumn{5}{|c|}{ Number of early pregnancy loss } \\
\hline $0(\mathrm{RC})$ & 1.00 & & 1.00 & \\
\hline $\mathrm{I}-3$ & 1.16 & $0.68-1.99$ & 1.67 & $0.72-3.85$ \\
\hline $4+$ & $3.56 * *$ & $1.48-8.55$ & $7.98 * *$ & $2.05-31.0$ \\
\hline \multicolumn{5}{|c|}{ Complication in index pregnancy } \\
\hline Yes (RC) & 1.00 & & 1.00 & \\
\hline No & $0.38^{* * *}$ & $0.23-0.64$ & 0.54 & $0.2 \mathrm{I}-1.35$ \\
\hline \multicolumn{5}{|l|}{ Place of delivery } \\
\hline Health facility (RC) & 1.00 & & 1.00 & \\
\hline Home/others & $5.32 * *$ & $2.06-13.7$ & 2.97 & $0.52-16.7$ \\
\hline \multicolumn{5}{|l|}{ Mode of delivery } \\
\hline Normal vaginal $(\mathrm{RC})$ & 1.00 & & 1.00 & \\
\hline Cesarean section & $2.33 * *$ & $1.34-4.06$ & 1.00 & $0.35-2.82$ \\
\hline Others & 2.84 & $0.86-9.33$ & 3.74 & $0.76-18.2$ \\
\hline
\end{tabular}

Notes: $* * * p<0.00$ I; $* * p<0.0$ I; and $* p<0.05$.

Abbreviations: $\mathrm{RC}$, reference category; $\mathrm{OR}$, odds ratio; $\mathrm{Cl}$, confidence interval.

In contrast, the major limitation of the study is its retrospective design and the fact that all cases of obstetric complications and maternal deaths may not have been captured due to poor record keeping in the hospitals. However, we made specific and rigorous efforts to ensure accurate data collection in the eight participating hospitals. Indeed, the need to ensure accurate data collection influenced our concentration of data collection in the immediate preceding year of the study in order to reduce the potential for recall bias and data mishandling. In particular, we used multiple approaches to identify all cases of maternal deaths in the hospitals. Thus, we believe that the results are accurate and represent the current state of maternal health and the delivery of emergency obstetric care in the referral hospitals.

We conclude that the independent risk factors for high MMR in Nigeria's referral hospitals include delivery in secondary health facilities, non-booking for pregnancy and delivery care, late referrals from nonhospital delivery outlets, and adverse maternal risk factors. Efforts to address these bottlenecks should include the improvement of emergency obstetric care in secondary care facilities, public health education so that women can seek appropriate and immediate evidence-based pregnancy care, and the socioeconomic empowerment of women. We believe that these reforms should be based on a systematic strengthening of the health care system in the country, so it can respond appropriately and effectively to the needs of women seeking emergency obstetric care.

\section{Acknowledgments}

Professor Eze Nwokocha (Medical Sociologist and Anthropologist, University of Ibadan) assisted with the qualitative data 
analysis. We are grateful to Dr Taiwo Oyelade and Dr Mariana Widmer of the Nigeria and Geneva offices of the World Health Organization for their support for the study. Funding was from the World Health Organization: Alliance for Health Policy and Systems Research grant/award number A65869 to the Women's Health and Action Research Centre (WHARC).

\section{Disclosure}

The authors report no conflicts of interest in this work.

\section{References}

1. World Health Organization. Trends in maternal mortality: 1990 to 2015. Estimates by WHO, UNICEF, UNFPA, World Bank and the United Nations Population Division. Geneva, Switzerland: World Health Organization; 2015. Available from: http://www.who.int/reproductivehealth/ publications/monitoring/maternal-mortality-2015/en/. Accessed July 29, 2017.

2. Alkema L, Zhang S, Chou D, et al [webpage on the Internet]. A Bayesian approach to the global estimation of maternal mortality. ArXiv151103330 Stat; 2015 [cited August 15, 2016]. Available from: http://arxiv.org/abs/1511.03330. Accessed August 15, 2017.

3. Alkema L, Kantorova V, Menozzi C, Biddlecom A. National, regional, and global rates and trends in contraceptive prevalence and unmet need for family planning between 1990 and 2015: a systematic and comprehensive analysis. Lancet. 2013;381(9878):1642-1652.

4. NPC, ICF International. Nigeria Demographic and Health Survey 2013. Abuja, Nigeria, and Rockville, MD, USA: National Population Commission, Nigeria and ICF International; 2014.

5. Mallick L, Tukur D, Kerry M. Trends in Maternal Health in Nigeria, 2003-2013: DHS Further Analysis Reports No 102. Rockville, MD, USA: ICF International; 2016.

6. Chinkhumba J, De Allegri M, Muula AS, Robberstad B. Maternal and perinatal mortality by place of delivery in sub-Saharan Africa: a meta-analysis of population-based cohort studies. BMC Public Health. 2014;14(1):1014.

7. Hussein J, Hirose A, Owolabi O, Imamura M, Kanguru L, Okonofua F. Maternal death and obstetric care audits in Nigeria: a systematic review of barriers and enabling factors in the provision of emergency care. Reprod Health. 2016;13(1):47.

8. Bazuaye A, Okonofua FE. Tackling maternal mortality in Africa after 2015: what should the priorities be? Afr J Reprod Health. 2013; 17(2):9-17.

9. Harrison KA. The struggle to reduce high maternal mortality in Nigeria. Afr J Reprod Health. 2009;13(3):9-20.

10. Oseji M, Ogu R. Community based interventions for the reduction of maternal mortality - the role of professional health associations, non-governmental organisations and community-based organisations in delta state, Nigeria. Niger Postgrad Med J. 2014;21(4):343-349.
11. Okonofua F, Ogu R, Agholor K, et al. Qualitative assessment of women's satisfaction with maternal health care in referral hospitals in Nigeria. Reprod Health. 2017;14(1):44.

12. Igwegbe AO, Eleje GU, Ugboaja JO, Ofiaeli RO. Improving maternal mortality at a university teaching hospital in Nnewi, Nigeria. Int $J$ Gynaecol Obstet. 2012;116(3):197-200.

13. Armstrong CE, Magoma M, Ronsmans C. Magnitude of maternal and neonatal mortality in Tanzania: a systematic review. Int $J$ Gynaecol Obstet. 2015;130(1):98-110.

14. Bauserman M, Lokangaka A, Thorsten V, et al. Risk factors for maternal death and trends in maternal mortality in low- and middle-income countries: a prospective longitudinal cohort analysis. Reprod Health. 2015;12(Suppl 2):S5.

15. Dumont A, Fournier P, Abrahamowicz M, Traore M, Haddad S, Fraser WD. Quality of care, risk management, and technology in obstetrics to reduce hospital-based maternal mortality in Senegal and Mali (QUARITE): a cluster-randomised trial. Lancet. 2013;382(9887):146-157.

16. Lee QY, Odoi AT, Opare-Addo H, Dassah ET. Maternal mortality in Ghana: a hospital-based review. Acta Obstet Gynecol Scand. 2012;91(1): $87-92$.

17. Gumanga SK, Kolbila DZ, Gandua BBN, Munkaila A, Malechi H, Kyei-Aboagye $\mathrm{K}$. Trends in maternal mortality in Tamale Teaching Hospital, Ghana. Ghana Med J. 2011;45(3):105-110.

18. Ntuli ST, Mogale M, Hyera FL, Naidoo S. An investigation of maternal mortality at a tertiary hospital of the Limpopo province of South Africa. South Afr J Infect Dis. 2017;32(2):73-76.

19. Wright K, Banke-Thomas A, Sonoiki O, Ajayi B, Ilozumba O, Akinola O. Opinion of women on emergency obstetric care provided in public facilities in Lagos, Nigeria: a qualitative study. Health Care Women Int. 2017; 38(6):527-543.

20. Okonofua F, Randawa A, Ogu R, et al. Views of senior health personnel about quality of emergency obstetric care: a qualitative study in Nigeria. PLoS One. 2017;12(3):e0173414.

21. Otolorin E, Gomez P, Currie S, Thapa K, Dao B. Essential basic and emergency obstetric and newborn care: from education and training to service delivery and quality of care. Int J Gynecol Obstet. 2015; 130(Suppl 2):S46-S53.

22. Okonofua FE, Abejide A, Makanjuola RA. Maternal mortality in Ile-Ife, Nigeria: a study of risk factors. Stud Fam Plann. 1992;23(5): 319-324.

23. Oladapo OT, Adetoro OO, Ekele BA, et al. When getting there is not enough: a nationwide cross-sectional study of 998 maternal deaths and 1451 near-misses in public tertiary hospitals in a low-income country. BJOG. 2016;123(6):928-938.

24. Hussein J, Okonofua F. Time for action: audit, accountability and confidential enquiries into maternal deaths in Nigeria. Afr J Reprod Health. 2012;16(1):9-14.
International Journal of Women's Health

\section{Publish your work in this journal}

The International Journal of Women's Health is an international, peerreviewed open-access journal publishing original research, reports, editorials, reviews and commentaries on all aspects of women's healthcare including gynecology, obstetrics, and breast cancer. The manuscript management system is completely online and includes

\section{Dovepress}

a very quick and fair peer-review system, which is all easy to use. Visit http://www.dovepress.com/testimonials.php to read real quotes from published authors. 